\title{
Molecular analysis of hepatitis B virus (HBV) in an HIV co-infected patient with reactivation of occult HBV infection following discontinuation of lamivudine-including antiretroviral therapy
}

Andrea Costantini ${ }^{1 \dagger}$, Katia Marinelli ${ }^{2}$, Giulia Biagioni ${ }^{2}$, Alessia Monachetti ${ }^{2}$, Monica L Ferreri ${ }^{2}$, Luca Butini ${ }^{1}$, Maria Montroni ${ }^{1}$, Aldo Manzin ${ }^{3}$ and Patrizia Bagnarelli ${ }^{2^{*}+}$

\begin{abstract}
Background: Occult hepatitis B virus (HBV) infection $(\mathrm{OBI})$ is characterized by HBV DNA persistence even though the pattern of serological markers indicates an otherwise resolved HBV infection. Although OBI is usually clinically silent, immunocompromised patients may experience reactivation of the liver disease.
\end{abstract}

Case presentation: We report the case of an individual with human immunodeficiency virus (HIV) infection and anti-HBV core antibody positivity, who experienced severe HBV reactivation after discontinuation of lamivudineincluding antiretroviral therapy (ART). HBV sequencing analysis showed a hepatitis B surface antigen escape mutant whose presence in an earlier sample excluded reinfection. Molecular sequencing showed some differences between two isolates collected at a 9-year interval, indicating HBV evolution. Resumption of ART containing an emtricitabine/tenofovir combination allowed control of plasma HBV DNA, which fell to undetectable levels.

Conclusion: This case stresses the ability of HBV to evolve continuously, even during occult infection, and the effectiveness of ART in controlling OBI reactivation in HIV-infected individuals.

\section{Background}

Occult hepatitis B virus (HBV) infection (OBI) is, by definition, characterized by infectious HBV DNA in liver, blood, or both, in the absence of hepatitis B surface antigens (HBsAg) [1]. Isolated anti-HBV core antibodies (anti-HBc) have been shown to be a predictive marker of OBI [2]. Isolated anti-HBc [3,4] and OBI are often seen in patients with human immunodeficiency virus (HIV) infection $[5,6]$, where they are more prevalent than in non-coinfected individuals [7]. Reactivation of chronic HBV in presence of HBsAg has been reported in immunosuppressed subjects and in those with HIV infection following discontinuation of antiretroviral therapy (ART) $[8,9]$.

\footnotetext{
* Correspondence: p.bagnarelli@univpm.it

+ Contributed equally

${ }^{2}$ Virology Unit, Department of Biomedical Sciences and Public Health,

Università Politecnica Marche, Via Tronto 10/a, 60020 Ancona, Italy

Full list of author information is available at the end of the article
}

There are few reports addressing OBI reactivation during HIV infection $[10,11]$ and fewer still providing an extensive description of the molecular characteristics of occult HBV reactivation [12]. Nucleot(s)ide analogues (NA) lamivudine, emticitabine and tenofovir are known to be effective against both HIV and HBV, providing a unique opportunity to treat coinfected patients $[13,14]$, but little information is available to establish whether resumption of ART for HIV/HBV coinfection may restore control of $\mathrm{HBV}$ replication after $\mathrm{OBI}$ reactivation.

\section{Case presentation}

A 46-year-old woman with a 25-year history of HIV disease, who experienced two episodes of occult HBV reactivation after interrupting a lamivudine-containing ART regimen. At the time of the diagnosis of HIV infection (October 1985) she also tested negative for HBsAg and positive for anti-HBsAg and anti-HBc (table 1). Lamivudine-containing ART was started in November 1996 and

\section{C) Biomed Central}


Table 2 Changes in ART during follow-up and reasons for each change.

\begin{tabular}{|c|c|c|c|c|c|}
\hline ART combination & Start & Stop & Reasons for the changes & $\begin{array}{l}\text { Lowest number of CD4+ T } \\
\text { cells } / \mathrm{mmc}\end{array}$ & $\begin{array}{l}\text { Highest HIV-RNA load } \\
\text { (copies/ml) }\end{array}$ \\
\hline Zidovudine, Lamivudine & $11 / 1996$ & $07 / 1997$ & Upgrade & 147 & - \\
\hline $\begin{array}{l}\text { Zidovudine, Lamivudine, } \\
\text { Saquinavir }\end{array}$ & 08/1997 & $02 / 2000$ & $\begin{array}{l}\text { Poor adherence, virological } \\
\text { failure }\end{array}$ & 50 & 90,387 \\
\hline $\begin{array}{l}\text { Stavudine, Lamivudine, } \\
\text { Efavirenz }\end{array}$ & $03 / 2000$ & $04 / 2000$ & Skin rash & 95 & 1,164 \\
\hline $\begin{array}{l}\text { Stavudine, Lamivudine, } \\
\text { Nevirapine }\end{array}$ & $05 / 2000$ & $08 / 2000$ & Patient decision & 65 & 1,245 \\
\hline INTERRUPTION & $09 / 2000$ & $01 / 2002$ & - & 9 & 472,578 \\
\hline Stavudine, Lamivudine & $02 / 2002$ & $04 / 2002$ & Upgrade & - & - \\
\hline $\begin{array}{l}\text { Stavudine, Lamivudine, } \\
\text { Lopinavir/r* }\end{array}$ & 05/2002 & 04/2003 & Patient decision, diarrhea & 74 & $<50$ \\
\hline $\begin{array}{l}\text { Tenofovir, Lamivudine, } \\
\text { Indinavir/r* }\end{array}$ & 05/2003 & $01 / 2009$ & Patient decision & 245 & $<50$ \\
\hline $\begin{array}{l}\text { Didanosine, Lamivudine, } \\
\text { Atazanavir }\end{array}$ & $02 / 2009$ & $04 / 2009$ & Simplification & 516 & $<40$ \\
\hline Lamivudine, Atazanavir & $05 / 2009$ & $09 / 2009$ & Patient decision & 531 & 119 \\
\hline INTERRUPTION & $10 / 2009$ & $02 / 2010$ & - & 291 & 80,558 \\
\hline $\begin{array}{l}\text { Emtricitabine/Tenofovir, } \\
\text { Darunavir/r* }\end{array}$ & $02 / 2010$ & - & - & 333 & 734 \\
\hline
\end{tabular}

${ }^{*} \mathrm{r}=$ boosted ritonavir.

Park, IL; limit of quantification 10 international units per millilitre $[\mathrm{IU} / \mathrm{mL}])$, and serological analysis revealed isolated anti-HBc. Attempts to obtain an overlapping polymerase and surface antigen sequence was successful with the May 2001 specimen, using a $5 \times$ concentration and nested PCR with inner primers $\mathrm{P} 2$ (forward inner = 5'-TCCTGTCCTCCAACTTGTCCTG) and P3 (reverse inner $=5$ '-TGTGGCAATGTACCCCAACTTCCA) that amplified a $571 \mathrm{bp}$ fragment internal to the $\mathrm{P} 1-\mathrm{P} 4$ product, from nucleotide 346 to 916 . This sequence showed the G145R and P142L, but not the D144DE HBsAg escape variant. The sample also contained the V224AV quasispecies, which was subsequently undetectable (table 3 and Figure 1). Although we cannot exclude that the different quasispecies were present in 2010, our date indicate that during the course of treatment, the species

Table 3 Genetic variability of hepatitis B virus during occult infection.

\begin{tabular}{|c|c|}
\hline \multicolumn{2}{|c|}{ Sequence information } \\
\hline Sample ID (HBV viral load) & SL05/2001 (19 IU/ml) \\
\hline Genotype (subtype) & $D\left(D 1-97.95 \%{ }^{1}\right)$ \\
\hline rt-HBV mutations: aa $79-255^{3}$ & $\mathrm{~N} 118 \mathrm{H}, \mathrm{Y} 135 \mathrm{~S}, \mathbf{R} 153 \mathrm{Q}, \mathrm{N} 248 \mathrm{H}^{2}$ \\
\hline s-HBV mutations: aa $71-227_{\text {stop }}{ }^{3}$ & R122K, P142LP, G145R, F179FS, V224AV² \\
\hline Escape mutations & $142 \mathrm{~L}, 145 \mathrm{R}$ \\
\hline Resistance prediction & None $^{4}$ \\
\hline Sample ID (HBV viral load) & SL02/2010 (88,185 IU/ml) \\
\hline Genotype (subtype) & $\mathrm{D}\left(\mathrm{D} 1-98.23 \%^{\mathbf{1}}\right)$ \\
\hline rt-HBV mutations: aa $43-330^{3}$ & $\mathrm{~N} 118 \mathrm{H}, \mathrm{Y} 135 \mathrm{~S}, \mathrm{R} 153 \mathrm{KQ}, \mathrm{N} 248 \mathrm{H}^{2}$ \\
\hline s-HBV mutations: aa $35-227_{\text {stop }}{ }^{3}$ & R122K, P142LP, D144DE, G145R, F179FS² \\
\hline Escape mutations & $142 \mathrm{~L}, 144 \mathrm{E}, 145 \mathrm{R}$ \\
\hline Resistance prediction & None $^{4}$ \\
\hline
\end{tabular}

${ }^{1}$ percent identity to the subtype as reported by HIV-GRADE_HBV-tool analysis (software available at http://www.hiv-grade.de/hbv_grade/deployed/grade.pl? program=hbvalg).

${ }^{2}$ mutated residues are defined with respect to the HBV genotype D consensus sequence, residues in bold indicate changes involving both rt and $s$ genes.

${ }^{3}$ aa = amino acid; the range of sequenced amino acid residues covers the whole region of rt-HBV involved by antiviral resistance and the "a" determinant neutralizing antibody-binding domains of the s-HBV gene; aa numbered according to Stuyver et al [26].

${ }^{4}$ the resistance prediction and reference sequence were assessed by HIV-GRADE_HBV-tool coupled with the interpretative algorithm Geno2Pheno [hbv] (available at http://hbv.bioinf.mpi-inf.mpg.de/index.php). 


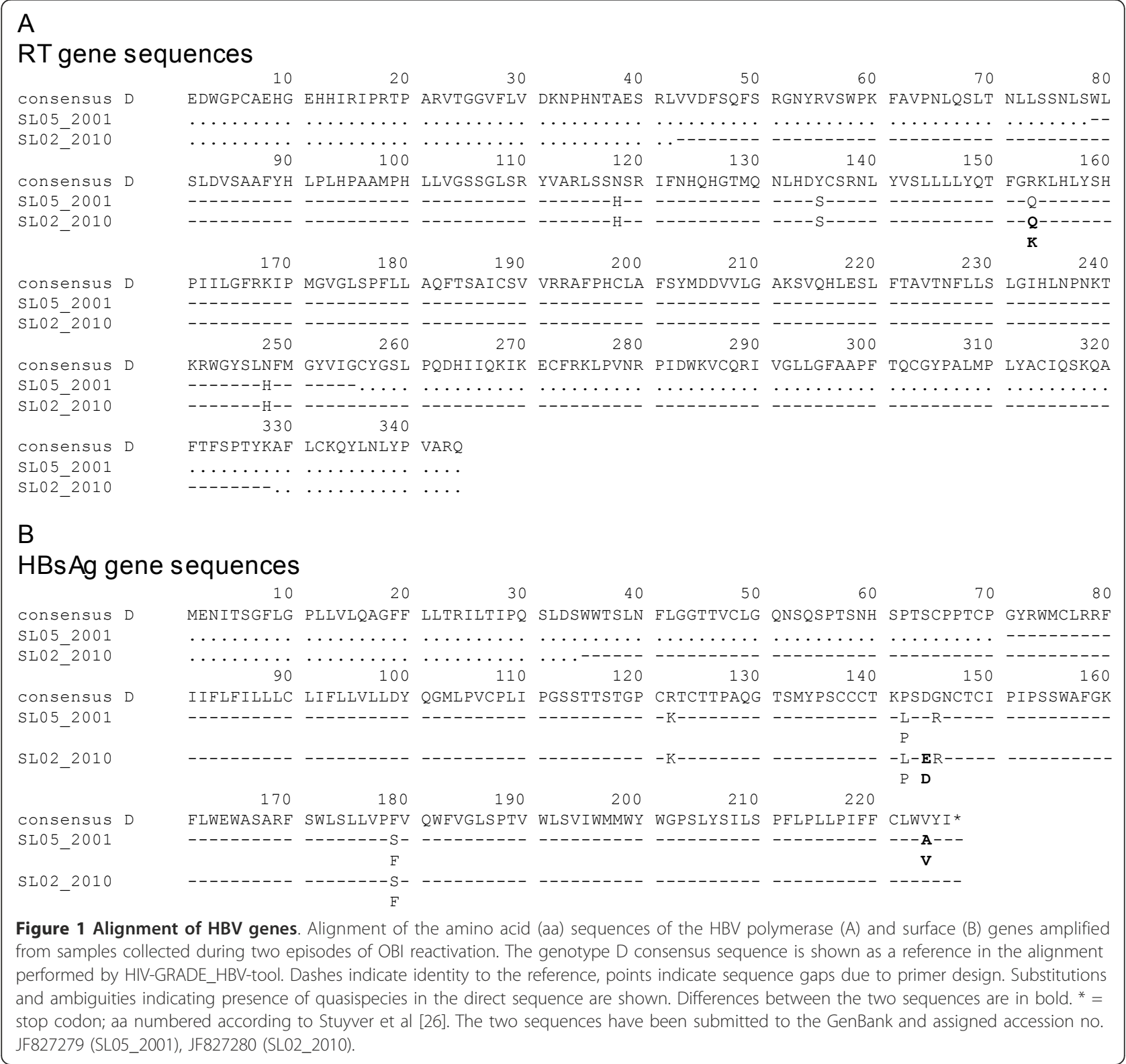

with D144E probably became more dominant and the species with V224A decreased in proportion. Altogether these data can be regarded as signs of HBV evolution: however, we acknowledge that lacking of cloning analysis of $\mathrm{HBV}$ quasispecies is a possible limitation to these conclusions.

The patient resumed ART to control HIV replication and counteract $\mathrm{HBV}$ reactivation. A regimen including emtricitabine/tenofovir plus boosted darunavir was prescribed in mid February 2010. After three months aminotransferase levels reverted to normal; follow-up of serological HBV markers showed the sequential disappearance of hepatitis B e antigen (HBeAg), IgM class
anti-HBc, and HBsAg. Plasma HBV DNA gradually fell to undetectable levels (table 1 ).

\section{Conclusions}

We describe the case of an HIV-infected patient with serological evidence of resolved HBV infection who experienced two distinct episodes of OBI reactivation after interrupting of lamivudine-containing ART regimens. In both cases, reintroduction of ART including $\mathrm{HBV}$-active NA (lamivudine or emtricitabine/tenofovir) was followed by aminotransferase normalization and clearance of plasma HBV DNA. Different results have been reported in two $\mathrm{HIV} / \mathrm{HBV}$ coinfected patients 
$[10,12]$. The reasons for the different outcomes are unclear, since only few cases of OBI reactivation among $\mathrm{HIV}$-infected individuals have been reported to date. Emergence of HBV drug resistance following OBI reactivation was observed neither in our patient nor in the one described by Bagaglio and co-workers [12]; residual HBV replication before the overt phase of occult HBV reactivation was excluded in both patients. However, residual HBV replication and reactivation without prior HBV DNA positivity have both been described in HIVinfected patients $[15,16]$.

Interestingly, OBI reactivation in our patient was treated with a drug combination including emtricitabine and tenofovir, while Bagaglio and co-workers used a single-drug tenofovir-based approach, and Chamorro and colleagues a scale up approach where tenofovir was introduced years after lamivudine [10]. Conceivably, different $\mathrm{HBV}$-active regimens may determine different outcomes in OBI reactivation, and combination therapy may have in principle better chances to obtain longterm control of HBV replication than single-drug regimens, especially in the context of HIV-related immune suppression.

One of the most intriguing aspect of HBV pathogenesis is the accumulation, already in the early phase of infection, of covalently closed circular (ccc)DNA in the nuclei of infected hepatocytes, which is the basis for the establishment of viral persistence. cccDNA is the hepatic reservoir for HBV infection, found in all patients studied up to a decade after resolution [17] and in 50\% of patients who had acute self-limited HBV infection 30 years previously [18]. Intrahepatic cccDNA can be considered as a candidate for OBI reactivation when immunological host conditions deteriorate.

In our patient molecular analysis of HBV DNA during reactivation disclosed an $\mathrm{HBsAg}$ escape variant, as shown by G145R and D144DE mutations in the HBsAg "a" determinant. Since HBV reinfection could not be completely ruled out, we analyzed the serum and plasma samples collected during the previous aminotransferase "blip", and found that the G145R variant was already present at that time.

Due to overlapping envelope and polymerase genes, the s-G145R variant is associated with the rt-R153Q mutation, which results in expression of an altered polymerase that is replication competent but seems to have reduced replication efficiency [19-21]. Among the few differences observed between the direct sequences of the 2001 and 2010 specimens, the s-HBV D144E variant seems to be important, since it determines a Q153K back mutation at the rt-HBV level. It is conceivable that rt-153K could be a secondary mutation connected with a fitness gain. Interestingly, coexistence of HBsAg and anti-HBs in 2010 specimens could be explained by presence of heterologous subtype-specific antibodies possibly directed against an HBsAg subtype different from HBsAg expressed in the past (primary) infection. At least five remarkable mutations were detected within the neutralizing epitope cluster of the surface protein in the genotype D consensus sequence, of which the D144E mutation has been described as a variant with "d" determinant opposite to the " $y$ " determinant more frequently detected in genotype D [22]. Although it is impossible to establish whether this variant emerged in the 9-year interval between the two OBI episodes, or during the latest reactivation, our data indicate that HBV evolution may have occurred during OBI, and that this and some other mutations may have led to the induction of less effective antibody response against a reactivated virus.

OBI reactivation is a consequence of deteriorated immune function $[23,24]$; in our patient the overt phase of severe HBV reactivation arose in conjunction with decreased CD4+ T cell counts. However, clinical and biochemical levels reflecting severe HBV reactivation were not observed at other times when the patient's immune status was profoundly impaired (see table 2): this was not a surprise, in that a severe reactivation of hepatitis $B$ requires a competent immune systems, and this is what happened during immune reconstitution in the absence of anti-HBV active drugs. Overall, it may be speculated that a qualitative, rather than a quantitative worsening of $\mathrm{HBV}$-specific $\mathrm{T}$ cell responses may favour OBI reactivation in HIV-infected patients. Notably, persistence of functional $\mathrm{T}$ cell response has been reported in individuals with OBI and in HBsAg-inactive carriers [25].

The clinical significance of occult hepatitis is still a matter of controversy and further studies should examine the long-term clinical implications of occult HBV in HIV-infected patients.

In summary, this case stresses that ART for HIV/ $\mathrm{HBV}$ coinfection can control OBI reactivation in HIVinfected individuals, and that in patients with previous HBV infection the withdrawal of anti-HIV drugs with activity against HBV must be approached with caution. Moreover, molecular HBV sequencing data support the hypothesis that HBV cccDNA, is not only the genetic archive for resistant viral genome emerging during treatment of chronic HBV, but also the genetic reservoir allowing continuous HBV evolution, through ongoing low-level replication, even during occult infection.

\section{Consent}

The study was approved by the institutional ethical committee of the Università Politecnica delle Marche. Written informed consent according to Helsinki 
protocol was obtained from the patient for publication of this case report.

\author{
Author details \\ ${ }^{1}$ Clinical Immunology Unit, Department of Clinical and Molecular Sciences, \\ Università Politecnica Marche, Via Tronto 10/a, 60020 Ancona, Italy. ${ }^{2}$ Virology \\ Unit, Department of Biomedical Sciences and Public Health, Università \\ Politecnica Marche, Via Tronto 10/a, 60020 Ancona, Italy. ${ }^{3}$ Section of Medical \\ Microbiology, Department of Biomedical Science and Technology, Università \\ di Cagliari, S.S.554, Bivio per Sestu, 09124 Monserrato (CA), Italy.
}

\section{Authors' contributions}

$A C, L B$ and $M M$ : have been involved in patient clinical care and carried out the standard immunological assays. AC, KM, MLF, AMa and PB: have been involved in acquisition and interpretation of data. GB, AMo and PB: carried out the standard and specific virological assays and the molecular and genetic studies. AC and PB conceived of the case presentation and drafted the manuscript. AC, PB and AMa reviewed the manuscript. All authors read and approved the final manuscript.

\section{Competing interests}

The authors declare that they have no relationship (commercial or otherwise) that may constitute a dual or conflicting interest. This paper was not supported by a research grant and was generated as part of routine activities.

Received: 12 July 2011 Accepted: 4 November 2011

Published: 4 November 2011

\section{References}

1. Raimondo G, Allain JP, Brunetto MR, Buendia MA, Chen DS, Colombo M, Craxì A, Donato F, Ferrari C, Gaeta GB, Gerlich WH, Levrero M, Locarnini S, Michalak T, Mondelli MU, Pawlotsky JM, Pollicino T, Prati D, Puoti M, Samuel D, Shouval D, Smedile A, Squadrito G, Trépo C, Villa E, Will H, Zanetti AR, Zoulim F: Statements from the Taormina expert meeting on occult hepatitis B virus infection. J Hepatol 2008, 49:652-657.

2. Raimondo G, Pollicino T, Cacciola I, Squadrito G: Occult hepatitis B virus infection. J Hepatol 2007, 46:160-170.

3. Neau D, Winnock M, Galpérine T, Jouvencel AC, Castéra L, Legrand E, Tranchant E, Balestre E, Lacoste D, Ragnaud JM, Dupon M, Lafon ME, Dabis F, for the Grupe d'Epidémiologie Clinique du SIDA en Aquitaine (GECSA): Isolated antibodies against the core antigen of hepatitis B virus in HIV-infected patients. HIV Med 2004, 5:171-173.

4. Pérez-Rodríguez MT, Sopeña P, Crespo M, Rivera A, Gonzáles del Blanco T, Ocampo A, Martínez-Vázquez C: Clinical significance of "anti-HBc alone" in human immunodeficiency virus-positive patients. World I Gastroenterol 2009, 15:1237-1241.

5. Morsica G, Ancarani F, Bagaglio S, Maracci M, Cicconi P, Cozzi Lepri A, Antonucci G, Bruno R, Santantonio T, Tacconi L, Baldelli F, Piscopo R, Santoro D, Lazzarin A, D'Arminio Monforte A, for the HepalCONA and the ICONA Study Groups: Occult hepatitis B virus infection in a cohort of HIVpositive patients: correlation with hepatitis $C$ virus infection, virological and immunological features. Infection 2009, 37:445-449.

6. Lo Re V, Frank I, Gross R, Dockter J, Linnen JM, Giachetti C, Tebas P, Stern J, Synnestvedt M, Russell Localio A, Kostman JR, Strom BL: Prevalence, risk factors, and outcomes of occult hepatitis B virus infection among HIVinfected patients. J AIDS 2007, 44:315-320.

7. Jardim RN, Gonzales NS, Pereira JS, Fais VC, Gonzales Junior FL: Occult hepatitis B virus infection in immunocompromised patients. Braz J Infect Dis 2008, 12:300-305.

8. Kusumoto S, Tanaka Y, Mizokami M, Ueda R: Reactivation of hepatitis B virus following systemic chemotherapy for malignant lymphoma. Int J STD AIDS 2009, 20:336-338.

9. Bellini C, Keiser O, Chave JP, Evison J, Fehr J, Kaiser L, Weber R, Vernazza P, Bernasconi E, Telenti A, Cavassini M, Swiss HIV Cohort Study: Liver enzyme elevation after lamivudine withdrawal in HIV-hepatitis B virus coinfected patients: the Swiss HIV Cohort Study. HIV Med 2009, 10:12-18.

10. Chamorro AJ, Casado JL, Bellido D, Moreno S: Reactivation of hepatitis B in an HIV-infected patient with antibodies against hepatitis B core antigen as the only serological marker. Eur J Clin Microbiol Infect Dis 2005, 24:492-494.

11. Clark SJ, Creighton S, Horner M, Smith HM, Portmann B, Taylor C, Cramp ME: Reactivation of latent hepatitis B virus infection with HIVrelated immunosuppression. Int J Int J STD AIDS 2006, 17:67-69.

12. Bagaglio S, Porrino L, Lazzarin A, Morsica G: Molecular characterization of occult and overt hepatitis B (HBV) infection in an HIV-infected person with reactivation of $\mathrm{HBV}$ after antiretroviral treatment interruption. Infection 2010, 38:417-421.

13. Soriano V, Vispo E, Bottecchia M, Sheldon J, Tuma P, Garcia-Samaniego J, Barreiro P: Management of hepatitis B virus co-infection on and off antiretroviral therapy. Curr HIV/AIDS Rep 2008, 5:86-93.

14. Martín-Carbonero L, Teixeira T, Poveda E, Plaza Z, Vispo E, González-Lahoz J, Soriano V: Clinical and virological outcomes in HIV-infected patients with chronic hepatitis B on long-term nucleos(t)ide analogues. AIDS 2011, 25:73-79.

15. Bhattacharya S, ljaz S, Ratnaraja N, Smith S, Osmana H, Boxall E: Hepatitis B virus reactivation in a large haemodialysis unit: Virological and infection control issues. J Clin Virol 2009, 46:101-103.

16. Bani-Sadr F, Maillard A, Ponscarme D, Scieux C, Molina JM: Reactivation of HBV replication in HIV-HBV infected patients. Am J Med 2003, 114:768-769.

17. Yuki N, Nagaoka T, Yamashiro M, Mochizuki K, Kaneko A, Yamamoto K, Omura M, Hikiji K, Kato M: Long-term histologic and virologic outcomes of acute self-limited hepatitis B. Hepatology 2003, 37:1172-1179.

18. Blackberg J, Kidd-Ljunggren K: Occult hepatitis B virus after acute selflimited infection persisting for 30 years without sequence variation. J Hepatol 2000, 33:992-997.

19. Locarnini S: Hepatitis B viral resistance: mechanisms and diagnosis. J Hepatol 2003, 39(suppl):124-132.

20. Coleman PF: Detecting hepatitis B surface antigen mutants. EID 2006, 12:198-203.

21. Bock CT, Tillmann HL, Torresi J, Klempnauer J, Locarnini S, Manns MP, Trautwein C: Selection of hepatitis B virus polymerase mutants with enhanced replication by lamivudine treatment after liver transplantation. Gastroenterol 2002, 122:264-273.

22. Pondé RA: The underlying mechanisms for the "simultaneous $\mathrm{HBsAg}$ and anti-HBs serological profile". Eur J Microbiol Infect Dis 2011.

23. Cohen Stuart JV, Velema M, Schuurman R, Boucher CA, Hoepelman Al: Occult hepatitis B in persons infected with HIV is associated with low CD4 counts and resolves during antiretroviral therapy. J Med Virol 2009, 8:441-445.

24. Tsui Il, Frennch AL, Seaberg EC, Augenbraun M, Nowicki M, Peters M, Tien PC: Prevalence and long-term effects of occult hepatitis $B$ virus infection in HIV-infected women. Clin Infect Dis 2007, 45:736-740.

25. Zerbini A, Pilli M, Boni C, Fisicaro P, Penna A, Di Vincenzo P, Giuberti T, Orlandini A, Raffa G, Pollicino T, Raimondo G, Ferrari C, Missale G: The characteristics of the cell-mediated immune response identify different profiles of occult hepatitis B virus infection. Gastroenterol 2008, 134:1470-1481.

26. Stuyver L, Locarnini SA, Lok A, Richman DD, Carman WF, Dienstag JL, Schinazi RF: Nomenclature for antiviral-resistant hepatitis B virus mutations inthe polymerase region. Hepatology 2001, 33:751-757.

\section{Pre-publication history}

The pre-publication history for this paper can be accessed here: http://www.biomedcentral.com/1471-2334/11/310/prepub

doi:10.1186/1471-2334-11-310

Cite this article as: Costantini et al:: Molecular analysis of hepatitis B virus (HBV) in an HIV co-infected patient with reactivation of occult HBV infection following discontinuation of lamivudine-including antiretroviral therapy. BMC Infectious Diseases 2011 11:310. 